\title{
A IMPORTÂNCIA DE UM CURRÍCULO COM ELEMENTOS AFROCENTRADOS PARA A CONSTITUIÇÃO DE UMA VISÃO EPISTEMOLÓGICA MENOS EUROCENTRADA
}

\author{
Rodrigo Fernandes Morais ${ }^{1}$ \\ Antonio Carlos Fontes dos Santos²
}

\section{RESUMO}

Pretendemos neste ensaio mostrar como o currículo eurocêntrico e as práticas pedagógicas eurocentradas perpetuam a colonialidade do saber e do ser, conduzindo o imaginário e as crenças de estudantes constantemente ao norte epistemológico. Ademais, de maneira breve, desvelar que, tanto a ciência hegemônica quanto as tecnologias, também foram construídas por cientistas africanas(os) e afrodiaspóricas(os) e, nesse sentido, buscando deixar um incentivo para que educadoras(es) de física e ciências possam trabalhar a superação da baixa autoestima e do sentimento de inferioridade que imobiliza estudantes negras(os) a partir dos exemplos que serão citados e de inúmeras referências que durante a roda viva da história tenham sido esquecidas, apagadas ou obliteradas.

Palavras-chave: Ensino de física. Cientistas. Colonialidade.

\section{THE IMPORTANCE OF A CURRICULUM WITH AFROCENTRATED ELEMENTS TO BUILD A LESS EUROCENTRATED EPISTEMOLOGICAL VISION}

\begin{abstract}
Our intention in this essay is to show how the Eurocentric curriculum and the Eurocentric pedagogical practices perpetuate the coloniality of knowledge and being, leading the students' imaginary and beliefs constantly toward the epistemological north. In this sense, our scope is to unveil that both the hegemonic science and technologies were also built by African and afrodiasporic Scientists and, in this sense, we seek to leave an incentive for the educators of physics and sciences to be able to overcome the low self-esteem and the feeling of inferiority that immobilize black students from the examples that will be cited and countless

\footnotetext{
1 Doutorando do Programa de Pós-Graduação em Ensino de Matemática (UFRJ). Orcid iD: http://orcid.org/0000-0001-7556-1708.E-mail: phy.arte@gmail.com

2 Professor Associado do Instituto de Física da Universidade Federal do Rio de Janeiro (UFRJ). Atua nos seguintes programas de pós-graduação: Programa de Pós-Graduação em Ensino de Matemática (PEMAT), no Programa de Pós-Graduação em Física, e no Mestrado Profissional em Ensino de Física, todos da UFRJ. Orcid iD: http://orcid.org/0000-0001-74026594. E-mail: toni@if.ufrj.br
} 
references that during the living wheel of history have been forgotten, erased or obliterated.

Keywords: Teaching physics. Scientists. Coloniality.

\section{LA IMPORTANCIA DE UN CURRÍCULO CON ELEMENTOS AFROCENTRADOS PARA CONSTRUIR UNA VISIÓN EPISTEMOLÓGICA MENOS EUROCENTRADA}

\section{RESUMEN}

En este ensayo mostramos como el currículo eurocéntrico y las prácticas pedagógicas eurocentradas perpetúan la colonialidad del saber y del ser, conduciendo el imaginario y las creencias de estudiantes constantemente hacia el norte epistemológico. Además, de manera breve, desvelamos que tanto la ciencia hegemónica como las tecnologías también fueron construídas por científicas(os) africanas(os) y afrodiaspóricas(os) y, en este sentido, buscamos dejar un incentivo para que educadoras(es) de física y ciencias puedan trabajar la superación de la baja autoestima y del sentimiento de inferioridad que inmoviliza a estudiantes negras(os) a partir de los ejemplos que serán citados y de innumerables referencias que durante la rueda viva de la historia hayan sido olvidadas, borradas 0 obliteradas.

Palabras clave: Enseñanza de lafísica. Los científicos. Colonialidad.

\section{INTRODUÇÃO}

A ciência e o cientista são conceitos muito difundidos no imaginário ocidental. Quando se estuda história da ciência ou dela toma-se conhecimento, tem-se a impressão que toda produção cientifica teve origem no ocidente. Em outras palavras, a idealização de que conceitos e teorias que sustentam a ciência foram elaborados no Hemisfério Norte, mais precisamente e majoritariamente em um único referencial geográfico: a Europa. Aparentemente, a região citada fora predestinada a fornecer a humanidade os seus mais importantes e geniais rebentos, integralmente pessoas comprometidas em trabalhos intelectuais complexos, toda a intelligentsia. Sendo assim, sempre que pensamos em um cientista, ou nos deparamos com a sua figura em um livro didático, sentimo-nos tentados a concordar com tal predestinação.

Desta forma, em contraposição a essa visão, julgamos que práticas educacionais de caráter afrocentrado se tornam fundamentais e 
necessárias. Principalmente se lembrarmos que a Europa resolveu se apropriar, com exclusividade, da prerrogativa de escrever a história de todo o resto do mundo (FINCH III; NASCIMENTO, 2009, p. 37). Se nos recordarmos que a partir do período, que ficou conhecido como século das luzes, toda a denominada intelligentisia europeia passou a se autoproclamar como superior intelectual e culturalmente, sendo a única capaz e qualificada para determinar a verdadeira história dos povos (FINCH III; NASCIMENTO, 2009, p. 37). Ademais, presumiam, baseados no milagre grego, que pertencia a Europa a exclusividade na elaboração de teorias e leis científicas. Um grande projeto de dominação inicialmente territorial que se converteu em dominação cultural e intelectual baseada na criação e propaganda da imagem de mitos e gênios ocidentais. Dessa forma, não causa surpresa constatar que os currículos de física são eurocentrados, machistas, heterossexistas, ocidentalcêntricos, colonialistas, imperialistas e, consequentemente, racistas.

Amparados pela Lei 10.639/2003 (BRASIL, 2003), pelas Diretrizes Curriculares Nacionais para a Educação das Relações Étnico Raciais e para - Ensino de História e Cultura Afro-Brasileira e Africana (BRASIL, 2004), consideramos que a ciência da natureza não deve se posicionar fora das fronteiras da missão solidária, a saber: a busca da desalienação, da decolonização, da diversidade, da equidade, da emancipação das identidades racializadas. Para isso, acreditamos que se faz necessário que a práxis de educar seja pautada: no antirracismo, no antissexismo, na antihomofobia, dentre outros. Em outros termos, acreditamos que o ensino de física e de ciências deve, agregado a outros saberes, rumar a partir do novo humanismo solicitado por Fanon em seu imprescindível livro Pele negra, máscaras brancas. ${ }^{3}$

Em uma sociedade governada por comportamentos e valores eurocentrados, que vive sob intensa colonialidade e, portando, intrinsecamente ligada a valores culturais da classe dominante

\footnotetext{
${ }^{3}$ FANON, F. Pele negra, máscaras brancas. Salvador: SciELO-EDUFBA, 2008.
} 
predominantemente caucasiana, consideramos a escola como peça fundamental no mecanismo da decolonização de grupos racializados.

Este ensaio almeja demonstrar em suas linhas, que após a implementação de práxis educacionais de caráter afrocentradas a colonialidade - que normatiza o processo de ensino e aprendizagem em Física, entre as(os) estudantes, foi reduzida.

Além disso, tais práxis educacionais tinham por finalidade reforçar a identidade de jovens negras(os) e reduzir possíveis complexos de inferioridade desses estudantes. Em outros termos, desconstruir possíveis imagens negativas de si introjetadas em relação ao mundo, bem como as referentes à área das exatas.

\section{A COLONIALIDADE E O ENSINO DE FÍSICA}

Muitos leitores, ao ter contato com um livro de física, podem ser induzidos a acreditar que as teorias e leis que explicam os fenômenos da natureza foram exclusivamente produzidas na Europa, e de lá irradiadas ao resto do planeta sendo, por consequência, universais e incontestáveis. Inevitavelmente, essa visão transmitida durante as aulas, orientada por currículos e materiais didáticos eurocentrados, corrobora para que estudantes assimilem a ideia errônea de que exclusivamente um grupo constituído por homens caucasianos europeus - foi predestinado a construir a ciência hegemônica. De maneira planejada ou não, esse tipo de apresentação unilateral cumpre o papel de omitir, negar ou obliterar a produção científica desenvolvida por grupos não brancos, como por exemplo cientistas africanas(os) e descendentes da diáspora africana. Cabe ressaltar que mesmo as(os) cientistas africanas(os) ou afrodiaspóricas(os), que também contribuíram para construção da ciência ocidental eurocêntrica, são esquecidos nos manuais de física; quer dizer, ainda que seguindo de perto as tradições, os pensamentos e os métodos científicos 
eurocentrados suas produções intelectuais e contribuições tecnológicas são contestadas e/ou invisibilizadas. ${ }^{4}$

O processo de ensino e aprendizagem em física nas escolas brasileiras se desenvolve profundamente enraizado em colonialidade e fundamentado no racismo epistêmico e no epistemicídio. O sociólogo porto-riquenho Ramón Grosfoguel argumenta que:

O racismo epistêmico considera os conhecimentos não-ocidentais como inferiores aos conhecimentos ocidentais. Se observarmos o conjunto de pensadores que se valem das disciplinas acadêmicas, vemos que todas as disciplinas, sem exceção, privilegiam os pensadores e as teorias ocidentais, sobretudo aquelas dos homens europeus e/ou euro-norte-americanos (GROSFOGUEL, 2007, p. 32).

O racismo epistêmico - assim como o epistemicídio - normatizado pela própria academia, desencadeia uma intensa "onda" de práticas guiadas pela colonialidade que se propaga através dos diversos cursos universitários. Consequentemente, embebecidos por pensadores e teorias brancocidentais ao longo de suas trajetórias acadêmicas, geralmente, docentes das diversas dimensões do ensino básico, convertem-se em educadoras(es) eurocentradas(os). Não é difícil constatar que a visão greco-ocidental ainda é hegemônica e domina currículos e atividades pedagógicas no espaço escolar. Nesse ponto, é importante mais uma vez destacar que mesmo as cientistas(os) negras(os)assim como as mulheres ocidentaisque se posicionam ao norte epistemológico ${ }^{5}$ não têm suas obras reconhecidas nos manuais de ciências.

Em particular, na física, normalmente durante as aulas estudantes entram em contato somente com nomes, a história e teorias de

\footnotetext{
4 Problematizando, é evidente que a simples presença de pesquisadores africanos ou afrodiaspóricos no desenvolvimento da ciência hegemônica não muda o caráter dessa ciência, pois esse saber é utilizado para desconstruir ou obliterar outros saberes (das diferentes culturas, ancestrais, consuetudinários, dentre outros). Entretanto, neste ensaio não será aprofundado especificamente a questão da colonialidade do saber em termos do poder hegemônico de um saber - por exemplo a própria física - sobre outros.

5 Pesquisadores dedicados aos estudos decoloniais não incluem aí somente/todos os europeus e norte-americanos, mas consideram euro-norte-americanos aqueles identificados como pertencentes ao norte global (que não é um lugar geográfico), em contraposição ao sulglobal.
}

Revista Exitus, Santarém/PA, Vol. 9, № 4, P. 66 - 94, Out/Dez 2019. 
representantes da ciência, como, a título de exemplo: Isaac Newton (16431727), Anders Celsius (1701-1744), Georg Simon Ohm (1789-1854), James Prescott Joule (1818-1889), André-Marie Ampère (1775-1836), ou seja, homens brancos de nacionalidade europeia ou americanos descendentes de europeus (MORAIS; SANTOS, p. 29).

Seguindo de perto este raciocínio, constata-se que a massificação de ensinamentos eurocentrados - pretensos universais - nas escolas terminam por fomentar nas mentes do corpo discente uma imagem de superioridade intelectual europeia e norte-americana. Por conseguinte, realizando um recorte que nos interessa neste ensaio, levantamos a hipótese de que efeitos da colonialidade ajudam a reforçar em estudantes negras(os), complexos de inferioridade do saber e consequentemente do ser, que podem afastálas(os) das diversas áreas do conhecimento. Aliado a isso, posições socioeconômica (históricamente) desfavoráveis contribuem fortemente para manter, também em nosso país, um caráter de branquitude nos diferentes cursos universitários, em particular e majoritariamente na área de ciências exatas.

\section{IDENTIFICANDO ASPECTOS DE COLONIALIDADE NO ENSINO DE FÍSICA}

Tendo por finalidade identificar/confirmar aspectos de colonialidade absorvidos por estudantes quando transmitidos/reforçados por aulas eurocentradas durante $\mathrm{o}$ ensino de física e ciências, foram realizadas inúmeras atividades ao longo do ano letivo de 2017 no Colégio Estadual Compositor Manacéia José de Andrade. 6 Neste ensaio, vamos destacar ações/atividades que aconteceram em três momentos diferentes.

Nas primeiras semanas do primeiro bimestre, em um primeiro momento, foi aplicado um questionário que continha a pergunta "Você saberia dar o nome de um físico? Qual?" A análise das respostas forneceu um panorama

\footnotetext{
${ }^{6}$ Colégio vinculado a SEEDUC-RJ, que homenageia Manacéia José de Andrade (1921-1995), mais conhecido como Manacéia que foi um compositor e instrumentista brasileiro. $O$ Colégio localiza-se no bairro de Madureira, na comunidade da Serrinha, mais precisamente na rua de acesso à entrada do morro de São José. Cerca de oitenta por cento (80\%) do corpo discente é composto por estudantes negras(os).
} 
preocupante. De um total de duzentos e vinte e nove (229) estudantes do ensino médio que responderam o questionamento: $44 \%$ não souberam citar um nome sequer, $47 \%$ citaram nomes de homens europeus (majoritariamente os nomes de Albert Einstein e Isaac Newton), 2\% citaram nomes de americanos e $1 \%$ citaram o nome de mulheres europeias, mais precisamente o nome de Marie Curie. Os $9 \%$ restantes, citaram o nome do professor de física, no caso, um dos autores deste ensaio.

No decorrer do primeiro bimestre, em um segundo momento, solicitouse aos estudantes das três séries do ensino médio que realizassem uma pesquisa sobre cientistas de exatas. Foi previamente explicado que a escolha do(a) cientista não deveria estar limitada à área da física. Com isso, esperávamos que a liberdade oferecida para a escolha os motivassem a pesquisar trajetórias científicas de personagens que de fato os interessassem.

Um total de cento e quarenta e seis trabalhos foram entregues, no qual cento e vinte e seis, ou seja, cerca de $86 \%$ não fugiram à "regra" do confinamento racial e de gênero em ciências, em outras palavras, os personagens escolhidos foram homens brancos, europeus ou americanos (Figura 1).

FIGURA 1: Número de trabalhos sobre cientistas entregues antes de serem implementadas as atividades/ações afirmativas

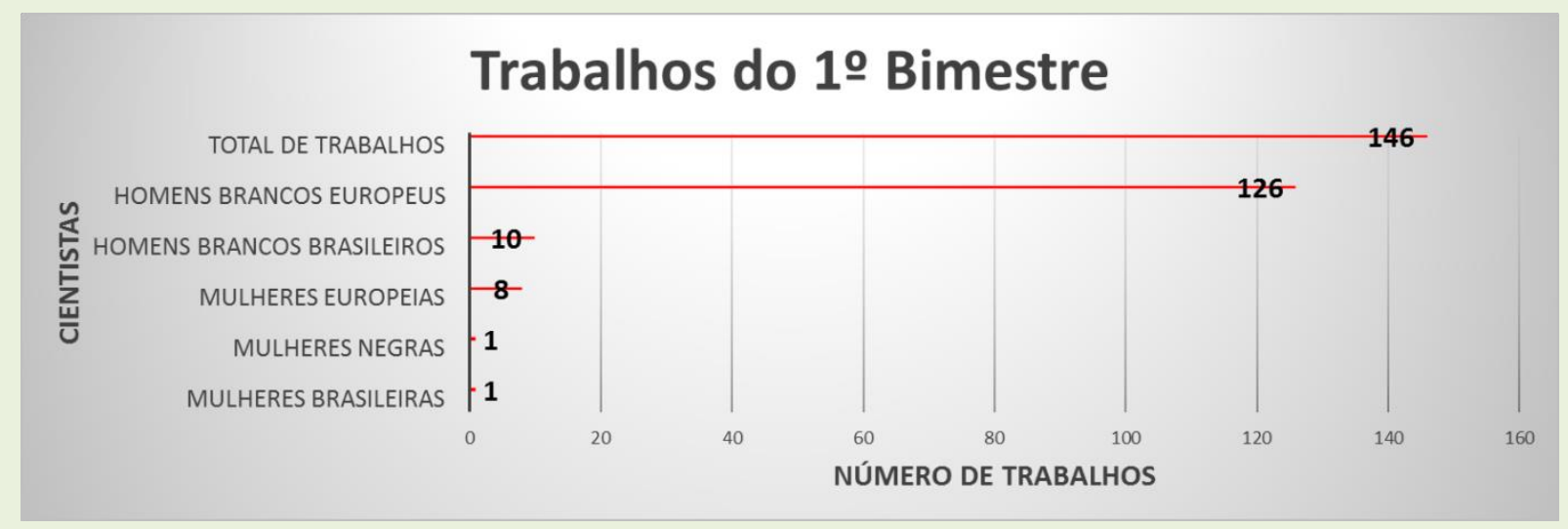

Fonte: MORAIS, R. F. Identidade racializadas e a atitude de negras(os) frente à física. 2019. 197f. Tese (Doutorado em Ensino e História da Matemática e da Física) - PEMAT-UFRJ, Rio de Janeiro. 
Somente dez trabalhos contavam as histórias e trajetórias científicas de cientistas brasileiros pelos alunos e alunas, e apenas dez trabalhos representavam as mulheres.

Desses dez trabalhos com representantes femininas, oito eram da mesma personagem, a cientista polonesa naturalizada francesa: Marie Curie. Uma única brasileira escolhida foi a neurocientista Suzana HerculanoHouzel e, apenas a história e trajetória científica de uma cientista negra, Shirley Ann Jackson, foi pesquisada por uma estudante do primeiro ano.

Durante as entrevistas, identificamos que a referida aluna já havia participado de atividades promovidas por movimentos sociais que defendem a causa negra. Desta forma, já tinha tido contato com a representatividade negra em outras áreas, em outras palavras, possuía alguns recursos ideacionais7 sobre o tema. Segundo ela: "tive a curiosidade de pesquisar uma cientista negra, pois acho importante que as pessoas conheçam [a cientista], já que quase não se vê negras em lugares altos [de destaque] na sociedade."

Ainda no primeiro bimestre, em um terceiro momento, foi aplicado um método indireto de pesquisa (ALMEIDA, 2015). Aliada as outras ações, este tipo de metodologia indireta nos permitiu que fossem identificados/confirmados aspectos de preconceito racial sustentados pela colonialidade arraigada no imaginário do corpo discente. Durante as aulas de física, duzentos e vinte estudantes de 16 turmas do ensino médio receberam uma folha (Anexo 1) que continha vinte e oito fotos de cientistas $^{8}$. Destes, dezoito eram brancos (uma mulher e dezessete homens), nove negros (duas mulheres e sete homens) e um oriental. Cada estudante deveria - marcando $\mathbf{S}$ para sim e $\mathbf{N}$ para não, em lacunas abaixo das fotos, dizer a partir da observação das fotos quem eles consideravam ou não

\footnotetext{
${ }^{7}$ Os recursos ideacionais são definidos como ideias que o indivíduo possui de si próprio e a sua relação e posição no mundo, bem como ideias sobre o que é valorizado e o que é considerado uma qualidade (NASIR, 2012).

${ }^{8}$ Mesmo correndo o risco de sermos anacrônicos, consideramos como cientistas neste trabalho homens e mulheres que ao longo da roda viva da história contribuíram para o desenvolvimento da ciência.
} 
consideravam cientistas. Foram computadas, folha por folha, as opções marcadas por cada estudante. Em outras palavras, as respostas das(os) estudantes (por cientista) passaram por contagem e em seguida lançadas em planilhas do Excel. Dessa forma, determinamos os percentuais de aceite e rejeição para cada cientista.

Cabe rassaltar que, entrevistas individuais foram estruturadas e realizadas para melhor compreender as respostas das(os) estudantes. Basicamente procurou-se diagnosticar as posições das(os) estudantes quando colocadas(os) frente às geografias humanas raciais distintas. A metodologia utilizada foi comparativa, ou seja, mostrava-se as(aos) estudantes entrevistadas(os) pares de fotos de cientistas que constavam no teste e questionava-se os motivos pelos quais as(os) levaram aceitar uma pessoa e recusar a outra como cientista. As respostas dadas foram gravadas e anotadas. As entrevistas comprovaram que no imaginário da maioria das(os) estudantes apenas os homens caucasianos estão aptos a exercer a função de cientista.

Perguntou-se, por exemplo, quais os motivos as(os) conduziram a aceitar (89\%) o austríaco Erwin Schrödinger como cientista e quais motivos as(os) levaram a refutar (82\%) o negro brasileiro André Rebouças. Os depoimentos apontavam majoritariamente para a diferença de cor entre os cientistas. Além disso, as análises dos depoimentos colhidos - antes das atividades/ações afirmativas implementadas - indicaram que uma fração substancial do grupo pesquisado considerava o homem branco com capacidade intelectual superior ao homem negro e às mulheres (brancas e negras).

Apresentaremos a seguir, brevemente, os dados provenientes da referida atividade, assim como nossas interpretações a respeito dos resultados encontrados. O produto dessas análises indicaram que o ensino de física colabora para a manutenção da colonialidade no espaço escolar. O fato é que dos dezessete homens brancos (de diversas nacionalidades, inclusive brasileira), doze foram aceitos como cientistas e cinco refutados. $O$ único representante da raça amarela também foi aceito pelos estudantes 
como cientista. Orientais frequentemente são considerados pessoas intelectualmente superiores em se tratando de ciências exatas. Entretanto, todos os homens negros apresentados nas fotos foram rejeitados como cientistas. Da mesma maneira, as três mulheres também não foram aceitas pelos estudantes como cientistas.

Após a dinâmica proposta, foram feitos debates e realizadas entrevistas com os (as) estudantes com a finalidade de desvelar os motivos pelos quais os levaram aceitar ou rejeitar, como cientistas, os personagens apresentados. Dentre os depoimentos sobre os personagens brancos que foram aceitos como cientistas podemos destacar argumentos como: "ele [Max Karl Ernst Ludwig Planck] tem cara de confiante", "sim, esse sim [Michael Faraday] tem cara de inteligente," "esse [José Leite Lopes] parece que sabe tudo" e "ele [Erwin Rudolf Josef Alexander Schrödinger] pelo cabelo, óculos, arrumadinho, é cientista" e "ele [DmitriMendeleev] tem jeito de tipo: eu sei muito." Dos personagens da ciência brancos que não foram aceitos como cientista, o mais comum foi a associação a políticos, como por exemplo nos casos de Richard Phillips Feynman e Wolfgang Ernst Pauli, que nas fotos usavam terno e gravata, assim como associação a artistas famosos como no caso de Werner Karl Heisenberg que foi classificado como "bonitão, artista de cinema", em clara assimilação ao padrão de beleza branco - eurocentrado - transmitido em primeira escala pela mídia e arraigado no tecido social.

Podemos considerar que o ponto fora da curva foi Isaac Newton. Consideramos um empate técnico, já que $51 \%$ dos alunos aceitaram que ele era um cientista e $49 \%$ rejeitaram-no. Mesmo provavelmente sendo o físico mais popular entre os estudantes, não foi reconhecido. Os alunos o consideraram um personagem da revolução francesa, um rei ou até mesmo o associaram a um personagem do filme Piratas do Caribe. A explicação se dá pelo fato de Newton na foto usar uma peruca de época.

Quanto a rejeição aos personagens da ciência negros, de uma maneira geral, as justificativas dos estudantes e das estudante reafirmaram a ausência de recursos ideacionais negros em suas trajetórias escolares. De 
maneira geral, as argumentações foram coincidentes, onde identificamos que a supressão da representatividade negra nos livros e, durante as aulas, cria no imaginário dos estudantes que o universo científico constituído exclusivamente por homens brancos: "Quando penso em um cientista penso em um cara branco, ele [André Pinto Rebouças] não tem cara de cientista" e "Professor, pelo padrão todos os cientistas são brancos, não é? Esse então [Lewis Howard Latimer] não pode ser".

Para problematizar, destacamos duas declarações esclarecedoras. A primeira a respeito de Rebouças (Figura 2) e a segunda a respeito de Carl Hart (Figura 3). Sobre Rebouças (refutado por $82 \%$ dos entrevistados) um estudante argumentou "Esse não é [cientista], aqui em Madureira, em cada esquina tem alguém parecido com ele".

FIGURA 2: André Pinto Rebouças

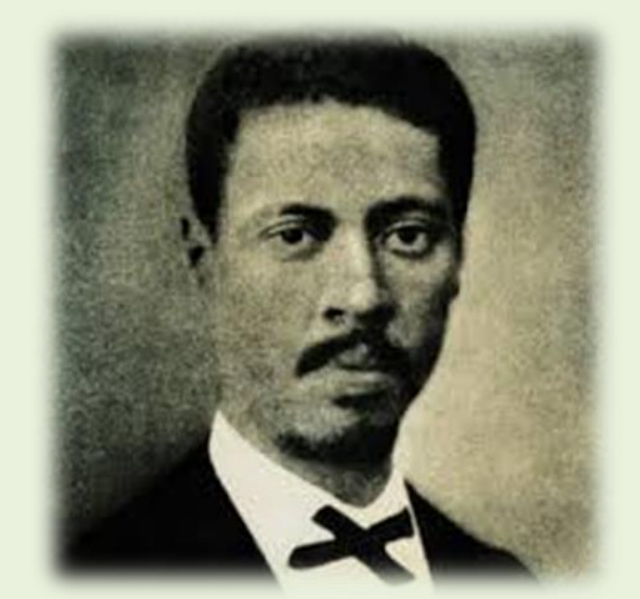

Fonte: SANTOS, S. M. G. dos. Andre'Rebouças e seu tempo. Rio de Janeiro: Sindicato Nacional dos Editores de Livros, 1985.

Mesmo entre especialistas ligados a exatas, a formação científica de Rebouças é ignorada. Rebouças bacharelou-se em Ciências Físicas e Matemáticas no ano de 1859, conquistando também o grau de engenheiro militar no ano de 1860. Sua figura é sempre invocada e vinculada ao 
abolicionismo e suas lutas políticas, secundarizando o valor de sua atuação como homem de ciência. ${ }^{9}$

Em outros termos, sua destacada atuação em projetos de infraestrutura viária e de saneamento no Brasil, durante o Segundo Reinado, ficam em segundo plano quando comparada a sua atuação como abolicionista. Para citar, Rebouças foi responsável por dirigir parte das obras das Docas da Alfândega e das Docas Pedro II, que modernizaram o porto colonial que existia na cidade, aumentando a capacidade de entrada e saída de mercadorias e a obra que garantiu o abastecimento de água da cidade do Rio de Janeiro na crise hídrica de 1869. Todas essas obras possuíam uma função social para a cidade e para o Império. Esses empreendimentos de engenharia representavam a materialização do progresso técnico e científico típico das mentalidades progressistas do século $X I X$.

Sobre $\circ \mathrm{PhD}$ em neurociência Carl Hart (refutado por $88 \%$ dos pesquisados), chamou atenção o depoimento: "Esse não é! Parece cantor de reggae, parece o Bob Marley."

FIGURA 3: Carl Hart

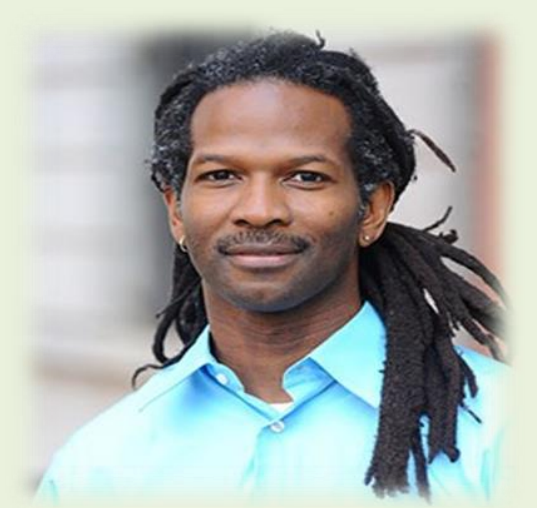

Fonte: https://www.tedmed.com/speakers/show? id=308946 (Acesso em 26.01.2019).

\footnotetext{
${ }^{9} \mathrm{O}$ termo homem da ciência era frequentemente utilizado nos textos do século XVIII e XIX, indicando a imposição/dominação do gênero masculino nas áreas científicas no referido período.
} 
Geografias humanas negroides semelhantes às de Rebouças e de Hart não estão incluídas nos livros de física em posições ligadas a ciência. Normalmente os negros são apresentados nos livros de física e de ciências como atletas ou em funções de trabalhadores braçais. As declarações confirmam que o contato, direto ou indireto, que alunos e alunas têm com tais características fenotípicas ocorrem, sobretudo, longe das aulas de ciências.

As personagens mulheres foram identificadas como escritoras, professoras e secretárias. Ora, a explicação é simples, afinal, estudantes estão acostumados a observar com regularidade representantes femininas exercendo essas profissões. Mulheres costumam, assim como negros, a serem apresentadas nos livros em posições afastadas da ciência. Além disso, chamou a atenção o depoimento sobre Marie Curie (preterida por $75 \%$ dos pesquisados): "mulher não podia ser [cientista] na época, e hoje em dia não tem quase nenhuma não é mesmo? Eu não lembro de nenhuma" onde o estudante nitidamente considerou em sua interpretação a roupa pouco usual para os nossos tempos que Curie vestia na foto e concluiu que somente homens poderiam ser cientistas no final do século XIX e início do século XX. E o mais alarmante, o estudante em seu depoimento deixou claro que não se lembrava se existiam representantes do gênero feminino colaborando para construção da ciência.

Além de depoimentos que levavam em consideração tanto o gênero quanto o fenótipo como requisitos preponderantes, por exemplo, sobre Mae Carol Jemison (Figura 4) um estudante afirmou: "ela não tem nenhuma aparência de cientista," por ser mulher e negra. A engenheira química, médica e primeira astronauta afro-americana M. C. Jamison foi preterida por $69 \%$ dos alunos e alunas que responderam a atividade. 
FIGURA 4: Mae Carol Jemison

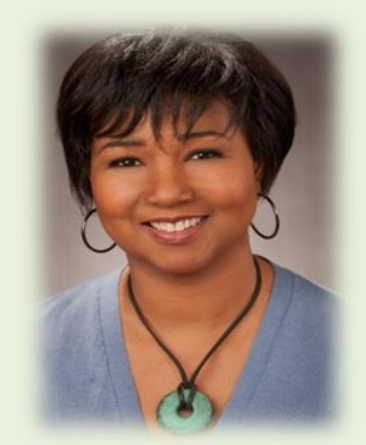

Fonte: https://www.gcfdn.org/News-Events/View-Article/Articleld/1360 (Acesso em 02.07.2018).

O fato é que temos ainda um número minoritário de mulheres, principalmente mulheres negras, em ciência (ROSA, 2015, p. 4) e para agravar o estado de invisibilidade, suas trajetórias científicas de sucesso são omitidas.

Embora negros e mulheres tenham contribuído de maneira substancial para ciência e avanços tecnológicos, suas histórias continuam aprisionadas, esquecidas ou eliminadas, afastadas dos livros didáticos e, salvo pelo esforço de alguns educadores e educadoras, distantes das práticas pedagógicas no espaço escolar.

\section{LIBERTANDO HISTÓRIAS APRISIONADAS: BREVES PROPOSTAS PARA DENEGIR 100 ENSINO DE FÍSICA}

Historicamente os envolvidos na construção dos currículos escolares dominantes em física e ciências não levam em consideração as características fenotípicas da população brasileira, que é constituída majoritariamente por pessoas negras. De maneira geral, os currículos sustentados no eurocentrismo não contemplam a cultura, as histórias de vitórias, muito menos a produção científica de negras(os). Enquanto currículos afrocentrados alternativos não são elaborados e implementados

\footnotetext{
10No senso comum o sentido do verbo denegrir é associado a ideia de manchar a boa imagem de alguém ou de uma instituição, através de atitudes ou declarações. Nesse sentido, é utilizado de maneira racista como sinônimo de algo ruim ou nocivo. Nesse ensaio utilizamos a palavra denegrir em seu sentido original: tornar-se negro.
} 
em nossas instituições de ensino, podemos a partir de ações/atividades afirmativas propor alternativas ao paradigma ocidental dominante.

No II Seminário de Formação Política de Grupo de Pesquisa em Políticas Públicas, Movimentos Sociais e Culturas - GPMC intitulado Pesquisar, Desobedecer, Agir para o Bem Viver realizado na UERJ, Catherine Walsh afirmou que devemos atuar nas rupturas. Argumentando que mesmo as super estruturas, por mais sólidas que pareçam, possuem fendas. Em acordo com o pensamento de Walsh, devemos atuar nas fendas do universo imperialista e colonizador eurocêntrico, buscando descolonizar não só as estruturas de poder que sustentam o processo de ensino e aprendizagem de física e de ciências, mas da mesma forma as mentes e, porque não dizer, os corações das(os) estudantes.

A partir de intervenções bem planejadas podemos apresentar aos(as) estudantes o protagonismo de cientistas africanas(os) e afrodiaspóricas(os) em diversos episódios da edificação da ciência. Episódios que são esquecidos, apagados ou obliterados pela historiografia hegemônica.

Por exemplo, a historiografia tradicional atribui a invenção da lâmpada ao norte-americano, descendente de holandês, Thomas Alva Edison. Edison desenvolveu seu protótipo de lâmpada incandescente de filamento de carbono em 1879. Porém, a historiografia não relata essas lâmpadas tinham vida útil muito baixa. Sendo assim, não poderiam ser comercializadas. Em outras palavras, o filamento da lâmpada de Edison se rompia com facilidade ao ser percorrido por uma corrente elétrica, em termos atuais, a lâmpada queimava rapidamente. Coube ao negro Lewis Howard Latimer (Figura 5/1848-1928) desenvolver e aplicar um processo que consistia na carbonização de tiras de materiais fibrosos ou têxteis, para produção de um filamento que não se rompesse com facilidade e, desta maneira, corrigisse o problema enfrentado pelo filamento da lâmpada original de Edison (MORAIS; SANTOS, 2017, p. 31). 
FIGURA 5: Lewis Howard Latimer

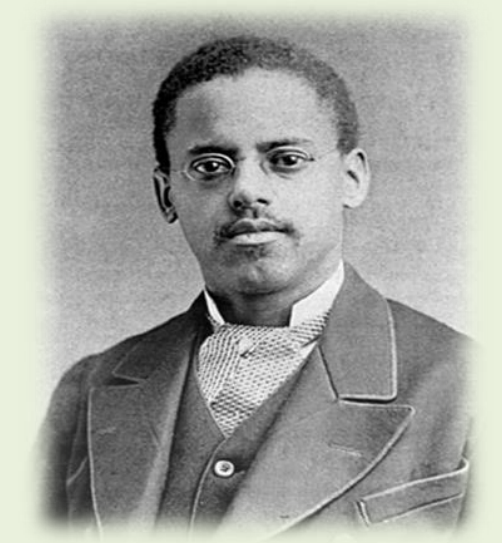

Fonte: MORAIS, R. F; SANTOS, A.C.F. LewisHowardLatimer e sua história aprisionada. A Física na Escola. v. 15, n.2, p. 29-33, 2017.

Infelizmente a historiografia tradicional parece ter "esquecido" esse importante personagem da história das ciências exatas, já que o nome de Latimer não costuma frequentar os relatos "oficiais" dos autores que escrevem sobre o episódio da invenção da lâmpada. Nesta invenção de imprescindível utilidade para a humanidade na era moderna, somente o nome Edison é lembrado.

Outra história aprisionada é a de Elijah McCoy (Figura 6/1844-1929). McCoy embora fosse um engenheiro mecânico, por ser negro, o melhor trabalho que conseguiu foi o de alimentador de carvão para os motores de locomotiva a vapor. Ainda assim, exercendo essa função e observando o funcionamento das máquinas, McCoy demonstrou toda sua perspicácia e inventou um dispositivo de lubrificação automático simples, porém, eficaz. Esse dispositivo revolucionou as indústrias ferroviárias e as máquinas térmicas da época (MACHADO, 2014, p. 121). 
FIGURA 6: Elijah McCoy

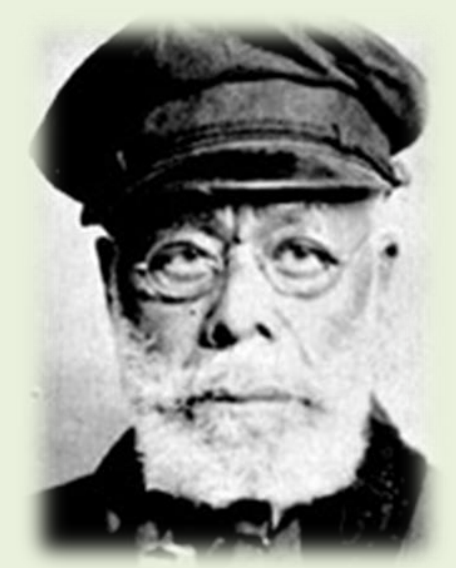

Fonte: MACHADO, C.E.D. Ciência, tecnologia e inovação africana e afrodescendente. Ed. Bookss, 2014. 378 p.

Não poderíamos esquecer de citar o pensador senegalês Cheikh Anta Diop (Figura 7/ 1923-1986). Diop era físico e egiptólogo e desafiou em sua época teóricos eurocentrados e seus paradigmas científicos dominantes. Solitariamente, Diop enfrentou acadêmicos que se levantavam contra ele em função de sua obstinação de enquadrar o Egito novamente no contexto da história africana (FINCH III, 2009, p. 73).

FIGURA 7: Cheikh Anta Diop

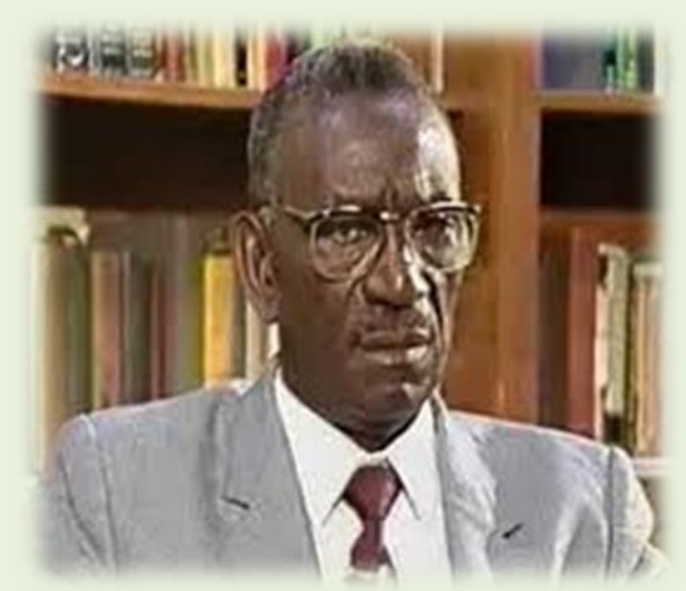

Fonte: $\quad$ https://jazzdagama.com/imperatives/cheikh-anta-diop-the-african-origin-ofcivilization-myth-or-reality/ (Acesso em 17.01.2019). 
Ademais, Diop em sua obra contestou a dita universalidade da ciência europeia e denunciou o projeto de dominação por trás de tal ideia. De acordo com Diop:

Muitas vezes, aquilo que o Ocidente designa de universalidade da ciência, da história ou da filosofia indica apenas o sentido do seu próprio conforto de viver e de dominar. O grau de universalidade que se atribui a si mesmo reflete uma aferição do peso do imperialismo - em boa consciência - que está dsposto a lançar sobre as nossas vidas. Com efeito, o imperialismo representa uma fonte de conforto (intelectual, social ou econômico) em detrimento do próximo (DIOP apud ELA, 2013, p. 11).

Em outros termos, o discursos que propõem-se científicos e por sua vez universais tem por finalidade sustentar a pretensa supremacia dos ocidentais sobre o restante da humanidade (ELA, 2013, p. 29).

Os exemplos citados/revelados, assim como suas histórias, podem ser trabalhados por educadoras(es) antenados a necessidade de ajuste curricular em física e ciências, para citar, tanto em aulas de eletricidade e termodinâmica tradicionais quanto em formato de rodas de conversas sobre ciência e sociedade, ou seja, nas fendas do próprio currículo dominante.

Não há surpresa no fato dessas histórias se encontrarem longe dos manuais de ciências, visto que quem as escreve é o próprio colonizador. Em outras palavras, a dita neutralidade científica, nesse aspecto pelo menos, tem um lado bem definido: brancocidental.

\section{ALGUNS RESULTADOS POSITIVOS APÓS AÇÕES/ATIVIDADES AFIRMATIVAS NO ESPAÇO ESCOLAR}

Ao final do terceiro bimestre, as(os) estudantes do C.E. Compositor Manacéia José de Andrade já haviam participado de inúmeras práticas educacionais de caráter afrocentrado. Em outras palavras, já haviam participado das atividades/ações afirmativas sustentadas pelas história de vida e producões científicas de cientistas afrodiaspóricas(os) e africanas(os). Lewis H. Latimer (1848-1928), André P. Rebouças (1838-1898), Elijah J. McCoy (1844-1929) Cheikh Anta Diop (1923-1983), Shirley Ann Jackson, Sônia 
Guimarães, dentre outras(os), foram apresentadas(os) para estudantes de 16 turmas do ensino médio. Essas atividades/ações afirmativas foram realizadas durante os tempos de aula de física, normalmente planajedas para acontecerem em 8 tempos de aulas por bimestre em cada turma, organizadas da seguinte maneira: 4 tempos eram para apresentação das histórias dos cientistas sob o formato oral com a utilização de slides, 2 tempos para apresentação de vídeos ${ }^{11}$ que problematizavam as relações raciais e, 2 tempos para rodas de conversas e debates - com a presença de educadoras(es) e estudantes - sobre temas como preconceito racial e racismo. Cabe ressaltar que, os vídeos apresentados durante as atividades/ações afirmativas demonstravam de que forma a sociedade com seus valores e padrões brancos - age sobre os sujeitos e pode influenciar e modificar o comportamento de mulheres negras e de homens negros em suas relações sociais.

À vista disso, no início do quarto bimeste, novamente solicitou-se que os discentes realizassem uma pesquisa sobre um cientista, mais uma vez sem imposição de nomes. Como no primeiro bimestre foi solicitado que o(a) cientista escolhido(a) tivesse sua trajetória ligada a exatas. Dessa vez, foi requisitado que os estudantes na introdução do trabalho, justificassem os motivos da escolha. Podemos verificar que algumas justificativas sustentaram, ainda que sob influência da colonialidade, a funcionalidade dos recursos Ideacionais. Para exemplificar, tomamos mão do relato de uma estudante do primeiro ano em um trabalho sobre Robert Hooke: "Eu resolvi escrever sobre Robert Hooke, porque eu estava assistindo uma série americana de documentário científico (Cosmos: A SpacetimeOdyssey) e um dos capítulos dessa série fala sobre Robert Hooke, no qual eu vi e me interessei bastante."

\footnotetext{
${ }^{11} \mathrm{https}$ ///www.youtube.com/watch? $\mathrm{v}=\mathrm{d}$ 9i-PJetE0o (Acesso 27.03.2017). https://www.youtube.com/watch? $v=d 7119 e G N s$ (Acesso 15.02.2017). https://www.youtube.com/watch? $v=h 0 h v 9 f g 88 n 8$ (Acesso 10.03.2017). https://www.youtube.com/watch? $v=O J m P E a M N N a M$ (Acesso 16.05.2017).
} 
Foram entregues um total de 189 trabalhos (Figura 8). Mesmo com a evasão escolar nos bimestres finais, o número de trabalhos realizados foi superior ao primeiro bimestre. O que de certa maneira, demonstrou o comprometimento dos estudantes com as propostas diferenciadas. Entretanto, mesmo após as atividades afirmativas, um total de noventa e nove trabalhos (cerca de 52\%) avaliados não fugiram a colonialidade, sendo os cientistas escolhidos homens, brancos, europeus ou norte-americanos.

FIGURA 8: Número de trabalhos sobre cientistas entregues após serem implementadas as atividades/ações afirmativas

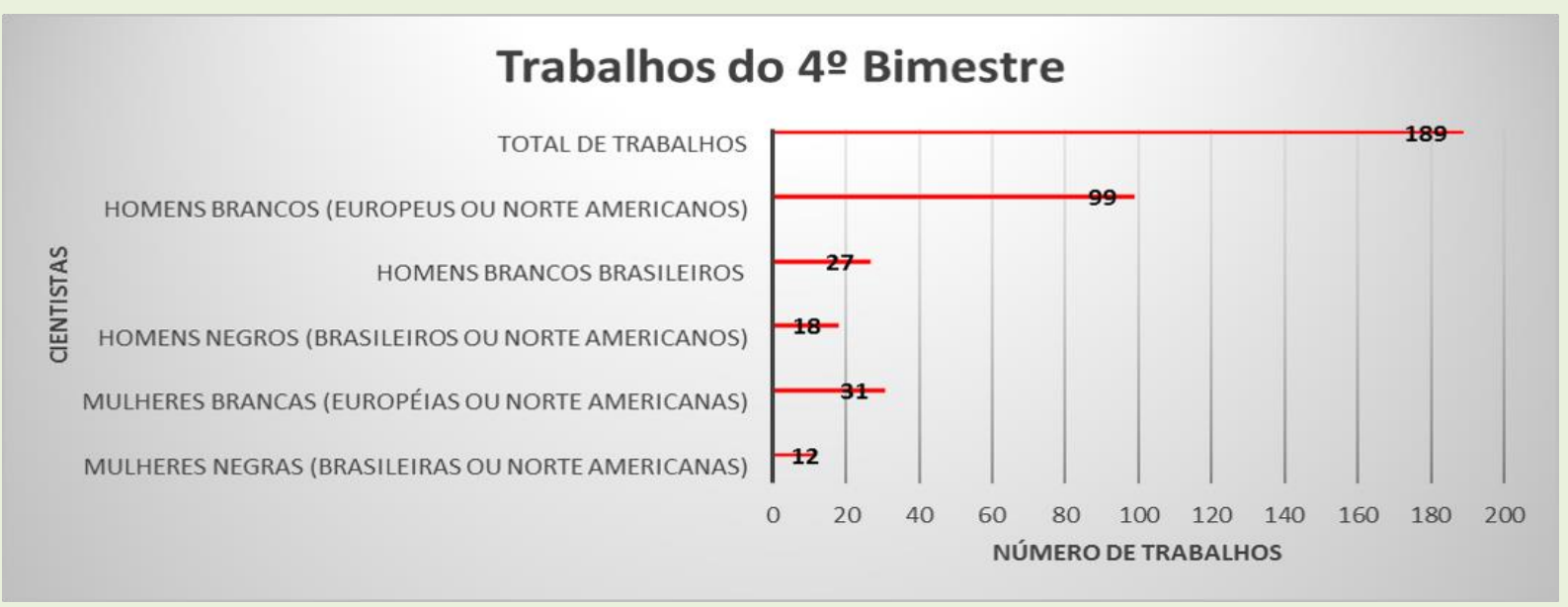

Fonte: MORAIS, R. F. Identidade racializadas e a atitude de negras(os) frente à física. 2019. 197f. Tese (Doutorado em Ensino e História da Matemática e da Física) - PEMAT-UFRJ, Rio de Janeiro.

Vinte e sete estudantes (cerca de $14 \%$ ) escolheram como cientistas homens brasileiros, no qual José Leite Lopes, César Lattes e Marcelo Gleiser foram preferidos. Sobre Leite Lopes, um estudante do primeiro ano redigiu: "Eu estava navegando na internet pesquisando [...] quando um me chamou a atenção, esse físico tinha uma coisa em comum comigo, o simples sobrenome."

Como relatado anteriormente, estudantes costumam ter o primeiro contato com cientistas a partir de leis, unidades, relações matemáticas ou até mesmo fenômenos físicos que recebem os seus sobrenomes. Por isso, a aparente surpresa e interesse inicial despertado por Leite Lopes, a partir da 
constatação do sobrenome em comum, não corriqueiro nos textos de livros didáticos.

Outra explicação que justificava a escolha do físico brasileiro Leite Lopes a ser destacada foi elaborada por um aluno do terceiro ano: "Eu achei esse físico através de um trabalho [que fiz] no primeiro ano e até hoje não esqueci dele porque[,] ele combateu a ditadura [...] a ditadura mexe comigo [,] por isso [,] tenho ele sempre comigo, é o único cientista não muito conhecido que ficou gravado na minha mente."

Lopes defendeu em sua trajetória acadêmica que a formação dos estudantes deveria ser completa, orientando aos jovens estudantes não perderem nenhuma dimensão do conhecimento. Aconselhando, por exemplo, jovens físicos a lerem sobre filosofia, sociologia, etc. (LOPES, 2000, p. 14). A caminhada das ciências exatas não é solitária, está sempre acompanhada por outros saberes. Ser lembrado por ter combatido a ditadura certamente deixaria Leite Lopes orgulhoso. Além do mais, na justificativa do aluno, extraímos mais um exemplo da funcionalidade e importância dos Recursos Ideacionais. Embora Leite Lopes tenha sido considerado pelo estudante um cientista "não muito conhecido," em algum momento de sua trajetória escolar, o estudante teve contato com esse personagem, tendo, como ele mesmo argumenta, o nome de Leite Lopes ficado gravado em sua mente.

Quarenta e cinco trabalhos (cerca de $24 \%$ ) eram de cientistas mulheres, divididas em trinta e uma caucasianas (americanas ou europeias) e doze negras (oito americanas e quatro brasileiras) e dois trabalhos sobre a Física chinesa ChienShiung Wu. Mais uma vez, Marie Curie foi a campeã de aparições entre as mulher, com um total de dezoito trabalhos. Destacamos 0 seguinte justificativa de uma aluna do segundo ano: "Eu escolhi Marie Curie porque foi a primeira mulher que eu conheci no meio científico e sempre tive a curiosidade de saber mais sobre ela."

Sua explicação pela opção de Marie Curie confirma que durante toda a sua vida escolar, Curie foi a primeira e única cientista mulher que ela teve 
contato. E que, quando teve oportunidade, este Recurso Ideacional - ainda que único - se fez presente e foi utilizado.

A brasileira Sônia Guimarães também foi lembrada, uma estudante negra do primeiro ano fez a seguinte observação: "Escolhi essa cientista por ser a primeira negra brasileira doutora em Física."

Conversando com a estudante após a entrega do trabalho, ela revelou: "eu mesma não sabia que existiam cientistas negras, o senhor sempre bate nessa tecla. Descobri em suas aulas." Perguntada sobre o que ela sentia, a resposta foi imediata: "orgulho!" Em seu trabalho de pesquisa a estudante constatou que Sônia sofreu duas vezes, por ser mulher e por ser negra em uma sociedade dominada por homens e pelo padrão branco.

Homens negros cientistas (aproximadamente 10\%) apareceram representados em um total de dezoito trabalhos. Neil de Grasse Tyson, apresentador da série Cosmos, foi lembrado por um aluno negro do primeiro ano que fez a seguinte afirmação ao justificar sua escolha pelo astrofísico: "Eu escolhi Tyson para este trabalho por conta de ser um dos maiores astrofísicos da atualidade. Eu também pretendo ser [astrofísico]. Ele produziu e apresentou uma série chamada Cosmos: uma odisseia no espaço-tempo, que é uma série que gosto muito."

O interesse pela astrofísica despertado no estudante nasce do seu contato com série científica Cosmos, um exemplo de como esse modelo de recurso ideacional pode influenciar os estudantes a definirem suas escolhas profissionais.

Ainda sobre Tyson, outro aluno do primeiro ano justificou que a escolha pelo apresentador foi motivada por considerá-lo um grande cientista e também pelo fenótipo do cientista, argumentando "[...] sem contar que ele é negro" e complementa "o que não é comum de ver [na ciência]."

Chama atenção, a tentativa de uma aluna negra do segundo ano explicar sua escolha de cientista e como ela, a sua maneira - porém, não equivocada - interpretou o que é e, como atuam a colonialidade e o racismo epistêmico: "Escolhi Lewis Latimer, porque como muitos outros, ele não foi reconhecido pelo seu trabalho "só" por causa da cor." 
Como resultado positivo, verificamos que após as atividades afirmativas realizadas, a visão dos alunos e das alunas a respeito do variado universo demográfico que constitui e constrói a ciência, ampliou sensivelmente. Cerca de $48 \%$ dos trabalhos se desvencilharam das amarras da colonialidade. Além disso, constatamos que histórias de cientistas que fogem ao universo de confinamento racial e de gênero dominante em ciências, quando reveladas em aula, colaboram para o processo de formação/reforço da identidade de jovens negras(os).

Cabe ressaltar que, com a sequência das práxis educacionais de caráter afrocentrados, resultados positivos continuaram acontecendo. Ao logo nas primeiras semanas de aula de 2018, estudantes que participaram da pesquisa em 2017 perguntaram se continuariam conhecendo "novos cientistas" e se seriam solicitadas novas pesquisas. A Figura 9 exibe capas de trabalhos sobre duas físicas negras brasileiras (Katemari Rosa e Sônia Guimarães) entregues ao longo do ano letivo de 2018. Na capa do trabalho sobre Sônia Guimarães a estudante descreve a motivação para realizar a pesquisa, segundo ela o motivo da escolha foi "[a] representatividade, [por Sônia ser uma] mulher brasileira e negra na ciência."

FIGURA 9: Capas de trabalhos feitos por estudantes do ensino médio do C.E. Compositor Manacéia José de Andrade

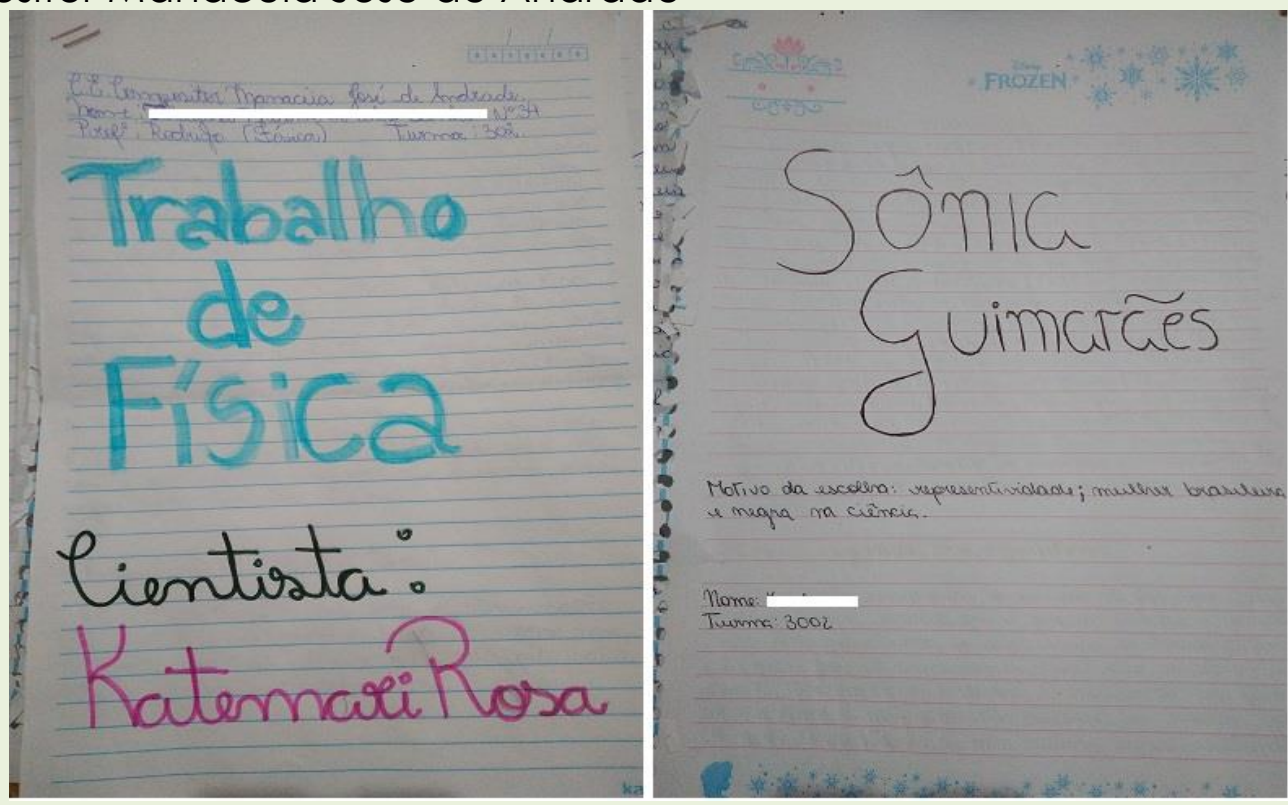

Fonte: Autor 1 


\section{CONSIDERAÇÕES FINAIS}

Os exemplos de cientistas negras(os) apresentados fazem parte de um pluriverso rico em exemplos, porém, esquecidos ou apagados pela historiografia tradicional escrita pelo colonizador. Identificada a obliteração dessas histórias, torna-se urgente desvelá-las. Torna-se improrrogável nos distanciarmos da visão monocultural das sociedades ocidentais (NOGUERA, 2012, p. 63). De maneira geral, em um país constituído majoritariamente por negras(os), por coerência, faz-se inadiável denegrir o ensino de física e de ciências.

É comum em nossas aulas apresentarmos somente homens da ciência de origem europeia: Newton, Celsius, Joule entre outros, todos comprovadamente espetaculares em suas áreas. Nesses compêndios há um desfile de cientistas europeus, euro-americanos ou europeizados, o que traduz em nosso imaginário a sentença capital de que apenas a Europa ou os brancos (o gênero empregado aqui é proposital) construíram os pilares da ciência. É importante destacar que esta assertiva não é uma exclusividade do campo da ciências exatas. Para citar, espaços acadêmicos tradicionais insistem há anos que o pensamento filosófico - ato de refletir sobre si mesmo e as ciências seriam universais e exclusividade do ocidente.

John Burnet no prefácio da terceira edição inglesa de sua tese clássica Early Greek Philosophy - publicada em 1892 e que sobrevive ainda hoje, diz que, "uma descrição adequada da ciência seria dizer que ela consiste em pensar sobre o mundo à maneira grega" (BURNET, 2006, p. 11). Porém, essa maneira greco-ocidental de ver, perceber e interpretar o mundo, que tem em Burnet um de seus principais arquitetos, vê agora os muros que a protegem serem acossados pelos que vivem à margem, pelos que de forma desafiadora pensam o mundo a partir do Sul e com o SUl (DE SOUSA, 2014). Dizer hoje que não há filosofia fora da Grécia, ou que ela nasce lá começa a gerar certos constrangimentos, denotando certa limitação de quem profere sentenças de natureza semelhante tendo em vista que fica cada vez mais claro o quanto esta tese é sectária e racista em sua formulação. 
O filósofo Renato Nogueira tem nos presenteado com uma produção acadêmica de qualidade e em diversas entrevistas tem divulgado novas perspectivas possíveis acerca do pensamento, um pensamento pluriversal. ${ }^{12}$ Nogueira, contrariando a perspectiva da tese tradicional, diz também que a Filosofia não teria nascido na Grécia, portanto não teria uma certidão de nascimento, tampouco local e ano de surgimento (NOGUERA, 2012, 2016). Para teóricos eurocentrados tanto a ciência moderna do século XVII e XVIII, da qual somos herdeiros, quanto a Filosofia estariam inseridas nessa esfera do milagre grego original. De acordo com essa visão - transmitida pelo colonizador - a exclusividade do pensamento seria europeia e branca. Ou seja, a única epistemologia plausível, travestida de neutra e universal, seria a masculina e branca (GROSFOGUEL, 2016). Não existindo para o pensamento nem o sumério, nem o chinês, nem o hindu, nem o muçulmano, nem o ameríndio. O conhecimento "superior" seria produzido por poucos homens ocidentalizados de cinco países apenas: Alemanha, França, Inglaterra, Itália e Estados Unidos da América (GROSFOGUEL, 2016). Seguindo essa lógica, estruturas civilizacionais extremamente complexas como as andinas seriam fruto de mero acaso. Seus feitos em matéria de engenharia e astronomia nem poderiam ser científicos, já que não há uma reflexão sobre a prática, pois, segundo Burnet, a filosofia e a ciência surgem na Europa.

É plangente que tenhamos que "provar" algo tão flagrante como a insustentabilidade de uma história única e de seus desdobramentos no discurso científico, epistemicamente centralizado na Europa. Entretanto, como suprarrelatado, basta abrirmos os livros didáticos para constatarmos a ausência de filósofos(as), matemáticos(as), físicos(as), químicos(as), biólogos(as), dentre outros(as), que não pertencem ao grupo dominante. Arriscamos dizer que hoje ainda é raro não vermos mais do que uma projeção desse ideário em nossos espaços escolares. É bom que se diga que a reivindicação que se faz aqui não é a de perscrutar toda a história da

\footnotetext{
${ }^{12}$ Ver: NOGUERA, R. Denegrindo a educação: Um ensaio filosófico para uma pedagogia da pluriversalidade. Revista Sul-Americana de Filosofia e Educação, n. 18, p. 62-73, 2012. Assim como: NOGUERA, R. Afroperspectividade: por uma filosofia que descoloniza. Revista África e Africanidades, Ano 3, n.11, 2010.
} 
humanidade em busca das origens da ciência, ou de dar proeminência a uma civilização em detrimento de outra, mas sim, de aceitarmos vários locais de produção do saber, de aceitarmos que o conhecimento é pluriversal.

Desta forma, levar ao conhecimento do alunado negro referencias de cientistas negros(as) retém triplo propósito. Primeiro, em conjunto com outros saberes, reduzir a colonialidade e o racismo epistêmico no ambiente escolar. Segundo, ao explorar a semelhança fenotípica, diminuir possíveis sentimentos de inferioridade do saber e do ser ao reforçar a identidade de estudantes negros e negras. Em terceiro, porém, não menos importante, despertar ou aumentar $o$ interesse de estudantes negros e negras pela física e pela ciência em geral.

\section{AGRADECIMENTOS}

Agradecemos à CAPES (programa Abdias Nascimento), assim como a professora de filosofia Fernanda C.S. Morais e os professores de sociologia Guilherme de Macedo Moreira e de história Ivan Cerqueira de Oliveira Silva pelos constantes debates e incessante colaboração.

\section{ANEXO 1}

NOME: TURMA:

Marque com $\mathbf{S}$ aquele que você acredita ser cientista e $\mathbf{N}$ para aquele que você acredita que não seja.
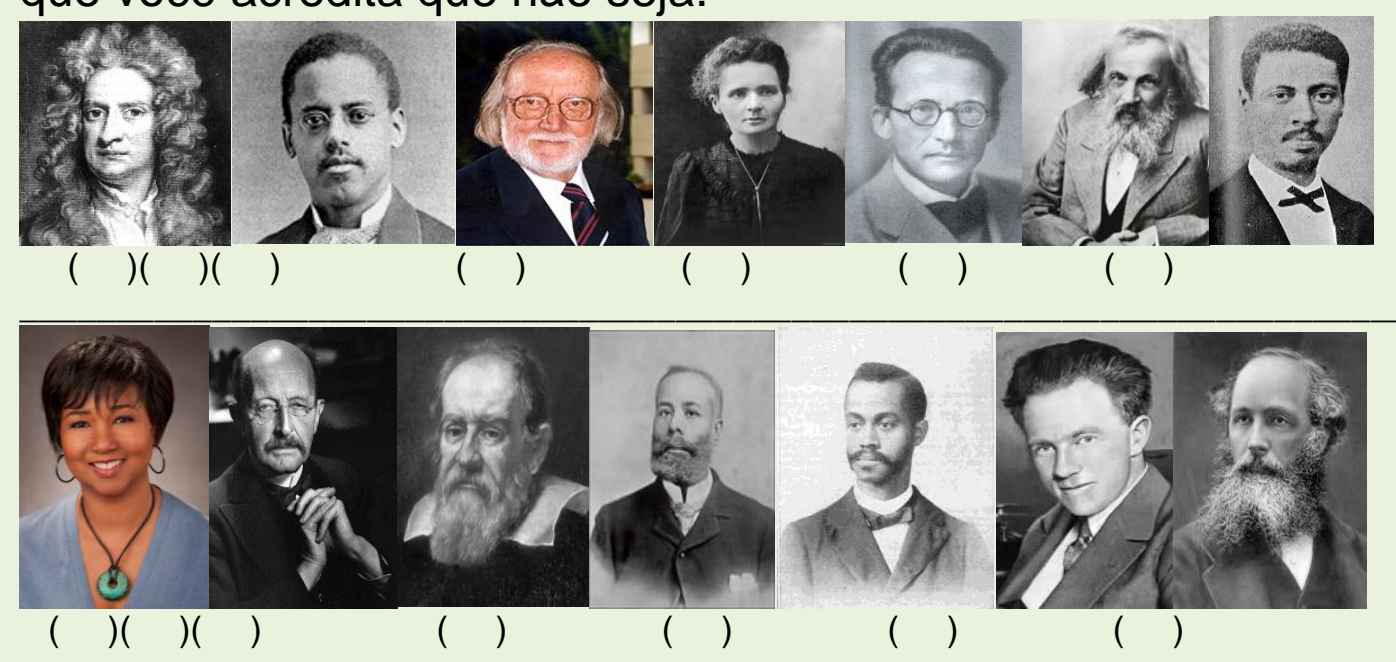

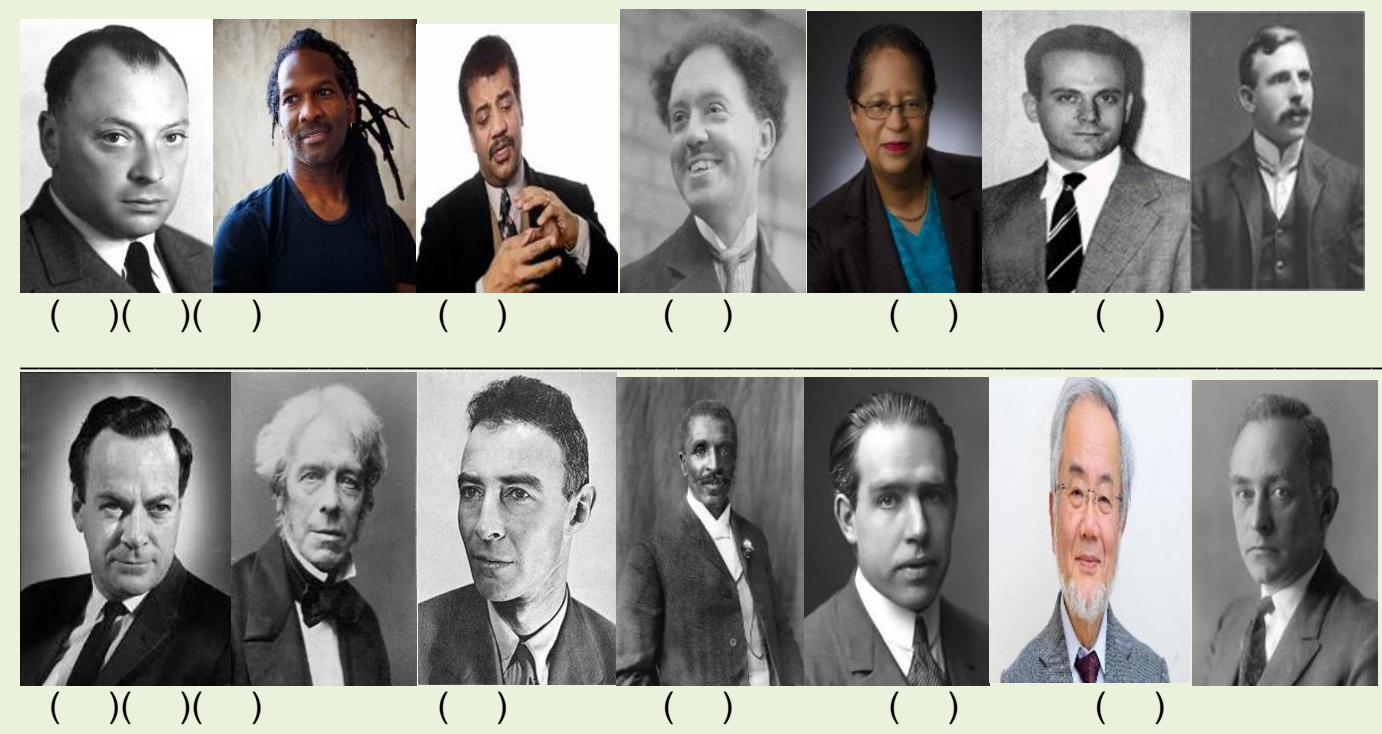

\section{REFERÊNCIAS}

AIMÉ, C. Discurso sobre o colonialismo. Portugal: Sá da Costa, Editora, 1978. $69 \mathrm{p}$.

ALMEIDA, A. C. A cabeça do Brasileiro. Rio de Janeiro: Record, 2015. 280 p.

BASTIDE, R; FERNANDES, F. Brancos e negros em São Paulo: ensaio sobre aspectos da formação, manifestações atuais e efeitos do preconceito de cor na sociedade paulistana. São Paulo: Global Editora, 2008. 332 p.

BICUDO, V. L. Atitudes Raciais de pretos e brancos em São Paulo. In: MAIO, M. C. (Org.). São Paulo: Editora Sociologia e Política, 2010. 192 p.

BOURDIEU, P. O Poder Simbólico. Lisboa: DI-FEL/Editora Bertrand1989. 313 p.

BOURDIEU, P; PASSERON, J. C. Os herdeiros: os estudantes e a cultura. Santa Catarina: Editora UFSC, 2014. 172 p.

BRASIL. Lei 10.639/2003. Brasília: Ministério da Educação, 2003.

BRASIL. Diretrizes Curriculares Nacionais para a Educação das Relações Étnico Raciais e para o Ensino de História e Cultura Afro-Brasileira e Africana. Brasília: MEC/SEPPIR, 2004. 35 p.

BURNET, J. A. Aurora da filosofia grega. Rio de Janeiro: Contraponto/PUC-Rio, 2006. 383 p.

DE SOUSA, B.S; MENESES, M. P. Epistemologias do Sul. São Paulo: Cortez Editora, 2014. 530 p.

ELA, J. Cheikh Anta Diop ou a honra de pensar. Ramada: Edições Pedago, 2013. $120 \mathrm{p}$. 
FANON, F. Pele negra, máscaras brancas. Salvador: SciELO-EDUFBA, 2008.

FINCH III, C. S. Cheik Anta Diop Confirmado. In: NASCIMENTO, E.L. (Org.). Afrocentricidade: uma abordagem epistemológica inovadora, São Paulo: Selo Negro, SANKOFA 4, p. 71-90, 2009.

FINCH III, C. S.; NASCIMENTO, E. L. Abordagem afrocentrada, história e evolução. In: NASCIMENTO, E.L. (Org.). Afrocentricidade: uma abordagem epistemológica inovadora, São Paulo: Selo Negro, SANKOFA 4, p. 37-69, 2009.

GROSFOGUEL, R. Dilemas dos estudos étnicos norte-americanos: multiculturalismo identitário, colonização disciplinar e epistemologias descoloniais. Ciência e cultura, v. 59, n. 2, p. 32-35, 2007.

GROSFOGUEL, R. A estrutura do conhecimento nas universidades ocidentalizadas: racismo/sexismo epistêmico e os quatro genocídios/epistemicídios do longo século XVI. Sociedade e Estado, v. 31, n. 1, p. 25-49, 2016.

MACHADO, C. E. D. Ciência, tecnologia e inovação africana e afrodescendente. Ed. Bookss, 2014. 378 p.

MORAIS, R. F; SANTOS, A. C. F. Lewis Howard Latimer e sua história aprisionada. A Física na Escola. v. 15, n.2, p. 29-33, 2017.

MORAIS, R. F. Identidade racializadas e a atitude de negras(os) frente à física. 2019. 197f. Tese (Doutorado em Ensino e História da Matemática e da Física) PEMAT-UFRJ, Rio de Janeiro.

NASIR, N.S. Racialized Identities: Race and Achievement Among African American Youth. California: Stanford University Press, 2012. 200 p.

NOGUERA, R. Afroperspectividade: por uma filosofia que descoloniza. Revista África e Africanidades, Ano 3, n.11, 2010.

NOGUERA, R. Denegrindo a educação: Um ensaio filosófico para uma pedagogia da pluriversalidade. Revista Sul-Americana de Filosofia e Educação, n. 18, p. 62-73, 2012.

SANTOS, A. C. F. YouDon't Look Like a Physicist.ThePhysicsTeacher, v. 55, p. 618-621, 2017.

SANTOS, S. M.G dos. André Rebouças e seu tempo. Rio de Janeiro: Sindicato Nacional dos Editores de Livros, 1985.

Endereços de internet:

Foto Mae C. Jamison. Disponível em: 
https://www.gcfdn.org/News-Events/View-Article/Articleld/1360 (Acesso em 02.07.2018).

Foto Carl Hart. Disponível em:

https://www.tedmed.com/speakers/show? id=308946 (Acesso em 26.01.2019).

FotoCheikh Anta Diop. Disponível em:

https://jazzdagama.com/imperatives/cheikh-anta-diop-the-african-origin-ofcivilization-myth-or-reality/ (Acesso em 17.01.2019).

Vídeo André Rebouças. Disponível em:

https://www.youtube.com/watch?v=OJmPEaMNNaM (Acesso 16.05.2017).

Vídeo cientistas e inventores negros. Disponível em:

https://www.youtube.com/watch?v=hOhv9fg88n8 (Acesso 10.03.2017).

Vídeo Neil deGrasse Tyson. Disponível em:

https://www.youtube.com/watch?v=d9i-PJetE0o (Acesso 27.03.2017).

Vídeo Pele negra, máscara branca. Disponível em:

https://www.youtube.com/watch? $v=d 7 \| 9 e G N s$ (Acesso 15.02.2017).

Recebido em: 27 de fevereiro de 2019

Aprovado em: 25 de agosto de 2019 